\title{
Effects of Lithium on cAMP-Dependent Protein Kinase in Rat Brain
}

\author{
Silvia Mori, Ph.D., Daniela Tardito, Ph.D., Alessandra Dorigo, Ph.D., Raffaella Zanardi, M.D., \\ Enrico Smeraldi, M.D., Giorgio Racagni, Ph.D., Jorge Perez, M.D., Ph.D.
}

We have investigated the effects of lithium treatment on cAMP-dependent protein kinase in discrete brain areas of rat by using photoaffinity labeling as well as western blotting. Lithium administered for 5 weeks resulted in a significant increase of the cAMP binding to the $52 \mathrm{kDa}$ cAMP-receptor in the soluble, but not in the particulate, fractions of both hippocampus and frontal cortex. Moreover, immunoblotting experiments revealed that chronic lithium treatment significantly increased the immunoreactivity against the regulatory and the catalytic subunits of the cAMP-dependent protein kinase in the soluble fraction of both brain areas. In contrast, no appreciable effect was observed in the particulate fractions. Short-term lithium treatment induced a significant increase in the immunolabeling of the catalytic subunits in the soluble fraction of both areas; whereas, the regulatory subunits and the actin were unchanged. In the particulate fractions, short-term lithium treatment did not elicit any substantial modification. Taken together, the results of the present study add to the growing evidence indicating that components of the cAMP signalling could play a crucial role in the biochemical action of lithium.

[Neuropsychopharmacology 19: 233-240, 1998] (C) 1998 American College of Neuropsychopharmacology. Published by Elsevier Science Inc.
KEY WORDS: Lithium; cAMP-Dependent protein kinase; cAMP Binding proteins; Regulatory subunits; Catalytic subunits; Hippocampus; Frontal cortex

In the last few years, studies from different laboratories have greatly expanded our knowledge about the role of postreceptor signal transduction in the pharmacotherapy and pathophysiology of affective disorders (Racagni et al. 1992; Hudson et al. 1993; Jope and Williams 1994; Manji et al. 1995; Hyman and Nestler 1996). The cyclic adenosine monophosphate (cAMP) pathway is a

From the Center of Neuropharmacology (SM, DT, AD, GR), Institute of Pharmacological Sciences, University of Milan, Milan, Italy; and Istituto Scientifico Ospedale San Raffaele (RZ, ES, JP), Department of Neuropsychiatric Sciences, School of Medicine, University of Milan, Milan, Italy; IRCCS San Giovanni di Dio (DT, GR), Sacred Heart Hospital-FBF, Brescia, Italy.

Address correspondence to: Dr. Silvia Mori, Center of Neuropharmacology, Institute of Pharmacological Sciences, University of Milan, Via Balzaretti 9, 20133 Milan, Italy.

Received February 23, 1998; accepted February 23, 1998. signal transduction system comprising a sequence of molecules whose function is to convey biochemical signals from surface receptors to cAMP-dependent protein kinase (PKA), a serine-threonine kinase that is the principal mediator of cAMP action in the central nervous system (Scott 1991). In the absence of cAMP, the PKA exists as an inactive tetrameric complex composed of a regulatory $(\mathrm{R})$ dimer and of two catalytic (C) subunits. Activation proceeds through a reaction where cAMP binds $R$ subunits, and the enzymatic complex subsequently dissociates into a $\mathrm{R}$ dimer and two free $\mathrm{C}$ subunits. Once released from the holoenzyme state, $\mathrm{C}$ moieties are able to phosphorylate many substrate proteins that regulate a great number of cellular functions (for reviews, see Scott 1991; Walaas and Greengard 1991).

Lithium salts are widely employed in the treatment of mood disorders (Wood and Goodwin 1987; Price and Heninger 1994). Although the biochemical basis underlying its therapeutic effects remains unknown, substantial data from experimental investigations suggest that 
most components of the cAMP signalling pathway are implicated in the lithium action (for reviews, see Jope and Williams 1994; Manji et al. 1995). For example, changes in $G$ proteins as well as in the calmodulin sensitive and insensitive forms of adenylate cyclase have been reported in rat brain following chronic lithium treatment (Mork and Geisler 1989; Newman et al. 1991; Li et al. 1991; Colin et al. 1991; Lesch et al. 1991; Masana et al. 1992). Additionally, it has been shown that either the phosphorylation state or the levels of some substrate proteins for the PKA are altered after long-term exposure to lithium (Caselbot and Jope 1991; Guitart and Nestler 1992; Rocha and Rodnight 1994). However, despite these observations, it remains to be answered whether PKA could be modulated by lithium treatment. Hence, the main aim of the present study was to investigate the cAMP binding activity and the PKA levels in discrete brain areas following short- and longterm lithium treatment.

\section{MATERIALS AND METHODS}

\section{Materials}

2-[N-morpholyne]-ethansulfonic acid (MES), Tris-(hydroxymethyl)-aminomethane (Tris), EGTA, EDTA, 3-isobutyl-1-methylxanthine (IBMX), aprotinin, pepstatin A, phenylmethylsulfonylfluoride (PMSF), cAMP, bovine serum albumin (BSA), lithium carbonate, the anti-actin antibody, and the peroxidase conjugate goat antimouse IgG were purchased from Sigma Chemical (St. Louis, MO). The antibody anti-regulatory subunit of PKA (RII) was from Biomol Research Labs, and the antibody against the catalytic subunit of PKA was from Transduction Lab. Enhanced chemiluminescence western blotting detection system (ECL), Hybond polyvinylidene difluoride (PVDF) membranes, and autoradiography films were obtained from Amersham (Braunschweig); $8-\mathrm{N}_{3}-\left[{ }^{32} \mathrm{P}\right]$-cAMP $(66.7 \mathrm{Ci} / \mathrm{mmol})$ from ICN (Irvine, CA). Molecular weight standards and all materials for gel electrophoresis and trans blot were from Bio-Rad. The bicinchoninic acid protein assay $\left(\mathrm{BCA}^{\mathrm{TM}}\right)$ was from Pierce.

\section{Lithium Administration}

Male Sprague-Dawley rats (initial weight $150 \mathrm{~g}$; Charles River, Calco, Italy) were used for all experiments. Animals were housed two per cage with free access to water and food and exposed to a $14 \mathrm{~h} \mathrm{light/dark} \mathrm{cycle.} \mathrm{In}$ the chronic study, 20 controls and 20 treated animals were given regular diet or pellets containing $0.24 \%(\mathrm{w} /$ w) lithium carbonate (Mucedola, Italy) for 5 weeks, as described elsewhere (Colin et al. 1991). Rats receiving chronic lithium gained weight at a slower rate than controls, similar to what was observed in a previous investigation (Colin et al. 1991); hypertonic saline (1.5\%) was available to prevent dehydration. An additional group of eight controls and eight treated rats receiving regular diet or a lithium carbonate-supplemented diet $(0.24 \%$ $\mathrm{w} / \mathrm{w})$ for 6 days was used in the acute study. Serum lithium levels were determined by atomic absorption spectrometry (the mean lithium levels \pm standard deviations were $0.94 \pm 0.14 \mathrm{mEq} / 1$ and $0.89 \pm 0.09 \mathrm{mEq} / 1$ after long- and short-term treatment, respectively).

\section{Photoaffinity Labeling and Western Blot Analysis}

All rats were sacrificed by decapitation and brains were quickly removed, dissected on ice, and stored at $-80^{\circ} \mathrm{C}$ until used. For analysis, frontal cortex or hippocampus obtained from different controls and treated animals were weighed and homogenized in 10 volumes of icecold buffer either Tris pH $7.4(10 \mathrm{mM}$ Tris- $\mathrm{HCl}, 2 \mathrm{mM}$ EDTA, $1 \mathrm{mM}$ DTT, $100 \mu \mathrm{g} / \mathrm{ml}$ leupeptine, $100 \mu \mathrm{g} / \mathrm{ml}$ aprotinin, 0.1 mM PMS-F) or MES pH 6.2 (50 mM MES, $10 \mathrm{mM} \mathrm{MgCl} 2,0.1 \mathrm{mM}$ EDTA, $2.5 \mathrm{mM}$ EGTA, $1 \mathrm{mM}$ DTT, $100 \mu \mathrm{g} / \mathrm{ml}$ leupeptine and $100 \mu \mathrm{g} / \mathrm{ml}$ aprotinin). The homogenate was centrifuged at $40,000 \mathrm{rpm}$ at $4^{\circ} \mathrm{C}$ for $30 \mathrm{~min}$.

The supernatant was used as the soluble fraction; whereas, the pellet was manually resuspended in the original volume of buffer and centrifuged at 40,000 rpm at $4^{\circ} \mathrm{C}$ for $30 \mathrm{~min}$. The pellet, corresponding to the particulate fraction, was dissolved in the same volume of Tris or MES (Walaas et al. 1983a, b). Total proteins concentration was determined using BCA protein assay; bovine serum albumin was used as the standard.

Photoaffinity labeling was performed as described in Perez et al. (1991). The reaction mixture, containing 40 $\mu \mathrm{g}$ of proteins in MES buffer $\mathrm{pH} 6.2$ and $1 \mu \mathrm{M} 8-\mathrm{N}_{3}-$ $\left.{ }^{32} \mathrm{P}\right]$-cAMP was incubated for $60 \mathrm{~min}$ in the dark at $4^{\circ} \mathrm{C}$, in the absence or presence of $100 \mu \mathrm{M}$ unlabeled cAMP. The samples were then irradiated with UV lamp at 254 $\mathrm{nm}$ for $10 \mathrm{~min}$. The reaction was blocked with an equal volume of Laemmli buffer (Laemmli 1970). An equivalent amount of proteins were fractioned by one-dimensional SDS-PAGE on $10 \%$ acrylamide. The dried gels were subjected to autoradiography, and the photoactivated $\left[{ }^{32} \mathrm{P}\right]$-cAMP binding to the protein bands was quantified by liquid scintillation.

For western blot analysis, $20 \mu \mathrm{g}$ of proteins were loaded on $12 \%$ acrylamide gels, fractionated by onedimensional SDS-PAGE and transferred to PVDF membranes $(0.45 \mu \mathrm{m})$ in a Bio-Rad Trans Blot electrophoresis apparatus at $100 \mathrm{~V}$ for 1 to $1.5 \mathrm{~h}$ in Towbins buffer (25 mM Tris, $192 \mathrm{mM}$ glycine, 20\% MeOH). Membranes were washed with TBS buffer pH 7.6 (20 mM Tris, 137 $\mathrm{mM} \mathrm{NaCl}$ ), soaked for $1 \mathrm{~h}$ in TBS buffer containing $0.1 \%$ Tween-20 (TBS-T) and 1\% albumin, and gently rinsed in TBS-T. All incubations were performed at room temperature. Different antibodies, anti-RII (1:300), anti-catalytic subunit $(1: 300)$ and anti-actin $(1: 5,000)$ were di- 
luted in TBS-T containing $1 \%$ albumin, added to the membranes and incubated for $90 \mathrm{~min}$. After $1 \mathrm{~h}$ washing in TBS-T, antibody-treated blots were incubated for $60 \mathrm{~min}$ in TBS-T containing 1\% albumin and peroxidase conjugate goat antimouse IgG (1:1000). Blots were then rinsed in TBS-T, and the immunoreactive bands were visualized by ECL and autoradiography. Levels of immunoreactivity for the recognized proteins were quantified using CCD camera and a software for image analysis (Image 1.44). The conditions used resulted in linear levels of immunoreactivity over a four-fold range of tissue concentration. Statistical analysis was performed using Student's $t$-tests.

\section{RESULTS}

As a first step in assessing the influence of chronic lithium treatment on PKA, we studied the cAMP binding proteins by photoaffinity labeling. As illustrated in Figure 1 (upper panel), lithium administered to rats under therapeutic conditions $(0.94 \pm 0.14 \mathrm{mEq} / \mathrm{l})$ for 5 weeks significantly enhanced the radioactivity incorporated into the $52 \mathrm{kDa}$ but not into the $47 \mathrm{kDa}$ (data not shown) cAMP receptors in the soluble fractions of both hippocampus and frontal cortex. In contrast, chronic lithium administration did not have any appreciable effect on the cAMP binding activity of the particulate fractions of the brain areas examined (Figure 1, lower panel).

Next, we assessed the levels of the $52 \mathrm{kDa}$ cAMPreceptor/RII as well as the $C$ subunits of PKA after lithium treatment either in the hippocampus or in the frontal cortex by using western blot analysis. The results showed that chronic lithium administration significantly enhanced the immunolabeling of RII subunits in the soluble fraction of hippocampus (Figure 2, upper panel) when compared to control animals. Moreover, long-term lithium treatment also led to a small, but significant, increase in the immunolabeling of the $C$ subunit of PKA (Figure 2, upper panel). These modifications seemed to be specific, because in the same fraction, the immunolabeling of actin, a cytoskeletal protein, was unchanged between controls and lithiumtreated animals (Figure 2, upper panel). In contrast, in the hippocampal particulate fraction, chronic lithium treatment did not alter the immunolabeling either of the PKA subunits or of the actin (Figure 2, lower panel).

Similarly to what was observed in the hippocampus, 5 weeks of lithium treatment significantly increased the immunoreactivity against the RII as well as the C subunits of PKA in the soluble fraction of frontal cortex without significant changes in the actin immunoreactivity (Figure 3, upper panel). Conversely, in the particulate fraction, lithium did not elicit changes in the immunolabeling of the PKA subunits and of the actin (Figure 3 , lower panel).
Finally, we evaluated the influence of the short-term lithium treatment $(0.89 \pm 0.09 \mathrm{mEq} / \mathrm{l})$ on PKA. Figure 4 reports the immunoreactivities against the PKA subunits and actin in the soluble fractions. Lithium administered for 6 days significantly increased the immunolabeling of the $C$ subunits either in the hippocampus (upper panel) or in the frontal cortex (lower panel) without affecting the immunolabeling of the RII subunits or of the actin. The experiments on the particulate fractions of both areas examined revealed that shortterm lithium treatment did not elicit any substantial alteration in the immunolabeling of the PKA subunits and of the actin (data not shown).

\section{DISCUSSION}

To the best of our knowledge, the current investigation is the first that examines the levels of the PKA, a crucial component in the cAMP signaling, following short- and long-term lithium treatment. The results demonstrate that long-term lithium treatment significantly increased the cAMP binding to the $52 \mathrm{kDa}$ cAMP-receptor as well as the immunolabeling of the PKA subunits in the soluble, but not in the particulate fractions, of hippocampus and frontal cortex. Moreover, short-term lithium treatment enhanced only the immunolabeling of the $\mathrm{C}$ moieties in the soluble fraction of both brain areas; whereas, any modification was detected in the particulate fractions.

Overall, the data reported here are complementary to previous findings showing that components of cAMP pathway are extremely sensitive to lithium (for reviews, see Jope and Williams 1994; Manji et al. 1995). Earlier binding data have reported that the administration of different reuptake blockers with antidepressant activity affected the cAMP binding to the $52 \mathrm{kDa}$ cAMP receptor in particulate fraction, specifically microtubules, of rat cerebral cortex (Perez et al. 1989, 1991). Our results clearly show that lithium treatment was able to enhance the cAMP binding only in soluble fractions of both hippocampus and frontal cortex. Immunological experiments using an antibody against the RII revealed that the increase in the cAMP binding activity by chronic lithium was attributable to an increase in the level of the $\mathrm{R}$ subunit. Interestingly, the $\mathrm{C}$ moieties of the enzyme were also found to be increased after chronic lithium treatment. In the soluble fraction, an increase in the immunolabeling of $C$ subunit was also observed after short-term lithium treatment; whereas, RII was unchanged. Recently, an inhibitory effect of lithium on PKA has been shown, possibly because of its competition with magnesium at the level of the $C$ subunit (Mori et al. 1996). The increase in the immunolabeling of $C$ subunit after short-term lithium treatment may be explained by a sort of compensatory mechanism in response to lithium inhibition. It is difficult to provide a 

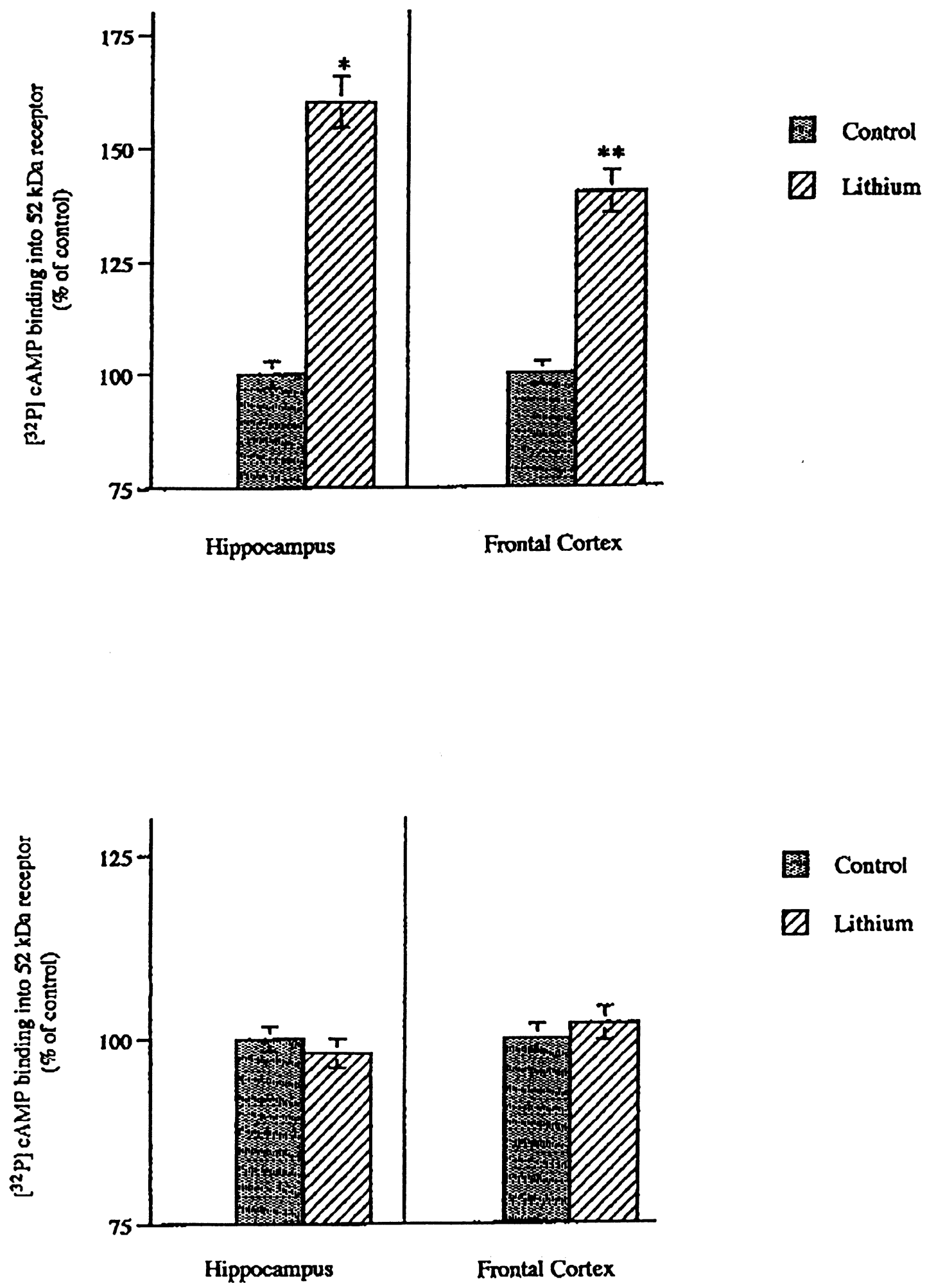

E Lithium

Figure 1. Effect of chronic lithium treatment on the [32 P]cAMP binding into the $52 \mathrm{kDa}$ receptor in the soluble (upper panel) and particulate (lower panel) fractions of hippocampus and frontal cortex. The results are expressed as percentage of controls and are the mean \pm standard deviation. ${ }^{*} p=.0001,{ }^{* *} p=.001$ (Student's $t$-test). 

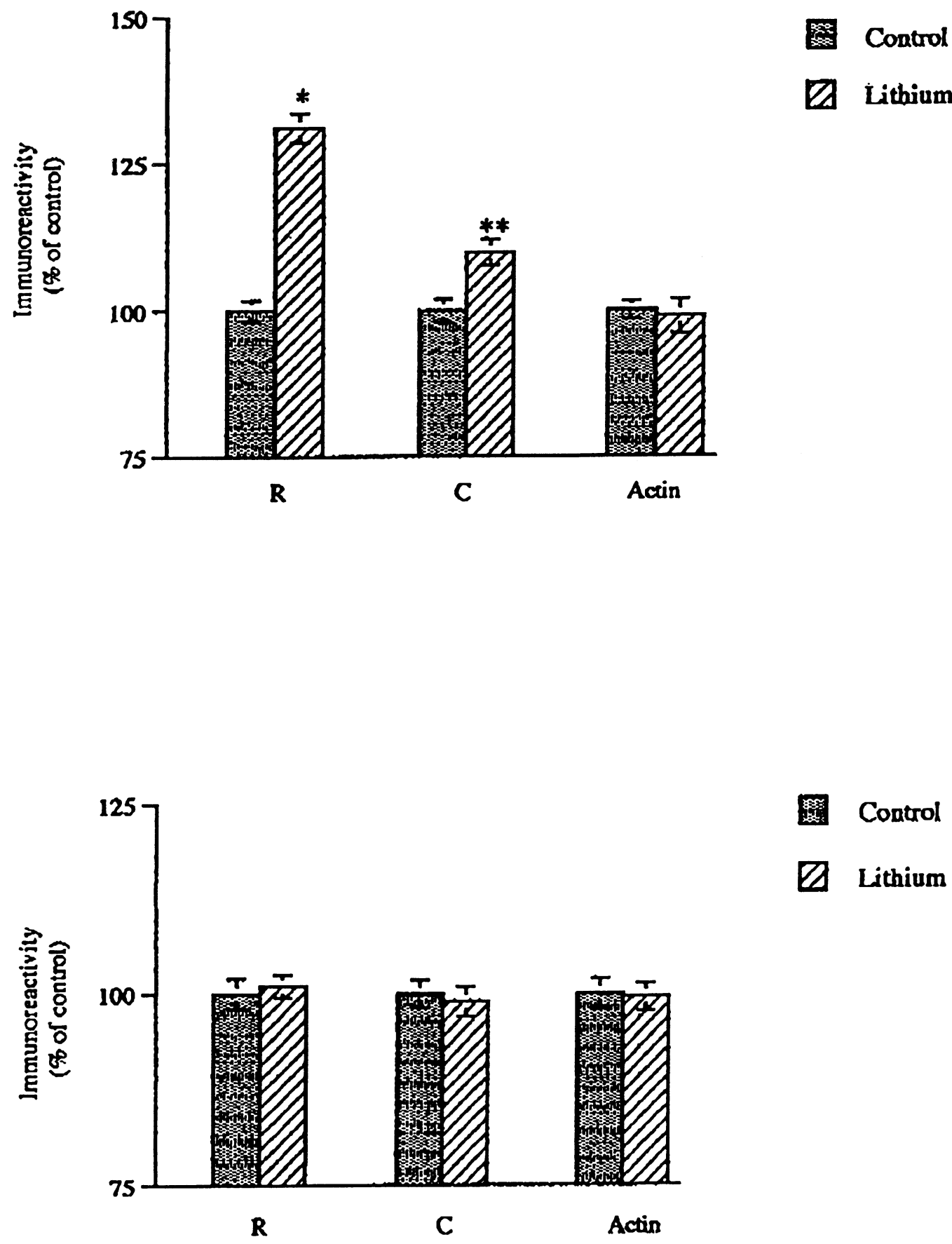

Figure 2. Influence of chronic lithium treatment on the immunolabeling of the regulatory (R) and catalytic (C) subunits of PKA and of actin in the soluble (upper panel) and particulate (lower panel) fractions of hippocampus. Data are expressed as percentage of control \pm standard deviation. ${ }^{*} p=.001,{ }^{* *} p=.04$ (Student's $t$-test).

clear explanation for the aforementioned hypothesis. On the other hand, lithium has been reported to alter the protein and mRNA levels of a number of components of signal transduction systems, and the mechanisms for these effects are still unknown (Jope and Williams 1994). The mechanisms that underlie the elevated levels of PKA subunits could involve either adaptation in cell function in response to lithium treatment or changes in mRNA processing and/or protein synthesis or degradation of PKA. Although lithium was shown to modulate the expression of genes coding for proteins involved in signal transduction, no change was observed after a short treatment period (Colin et al. 1991; Jope and Williams 1994).

Another possibility is a different subcellular redistribution of the R subunit of the PKA following a pharma- 


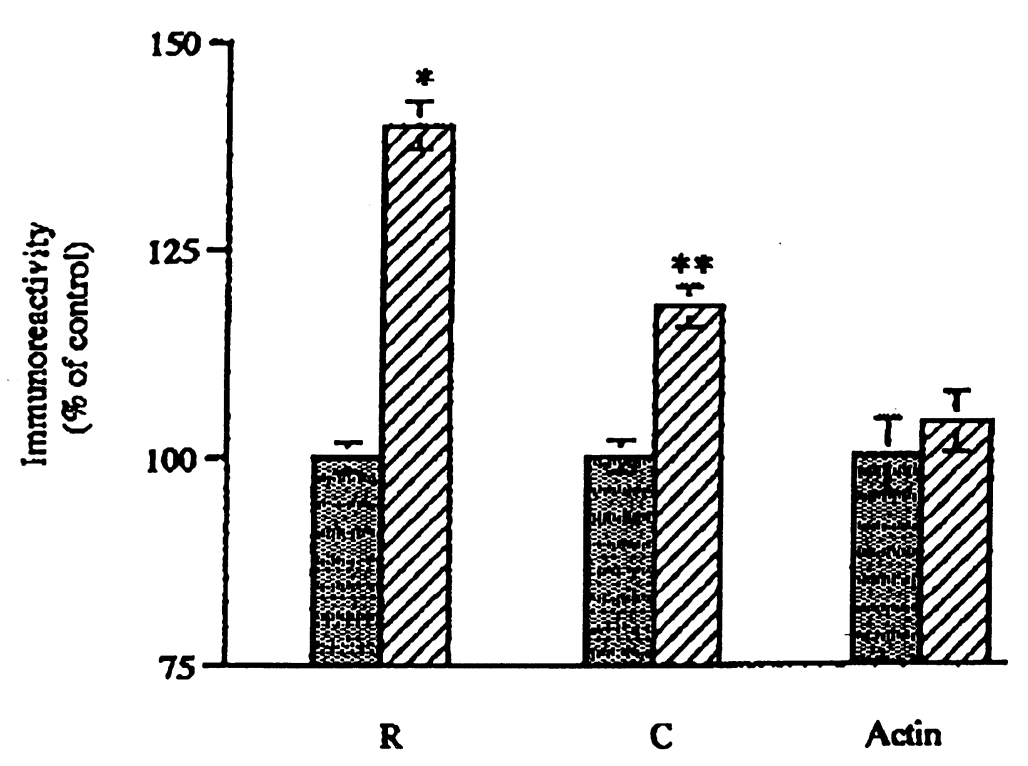

\section{Control \\ Lithium}

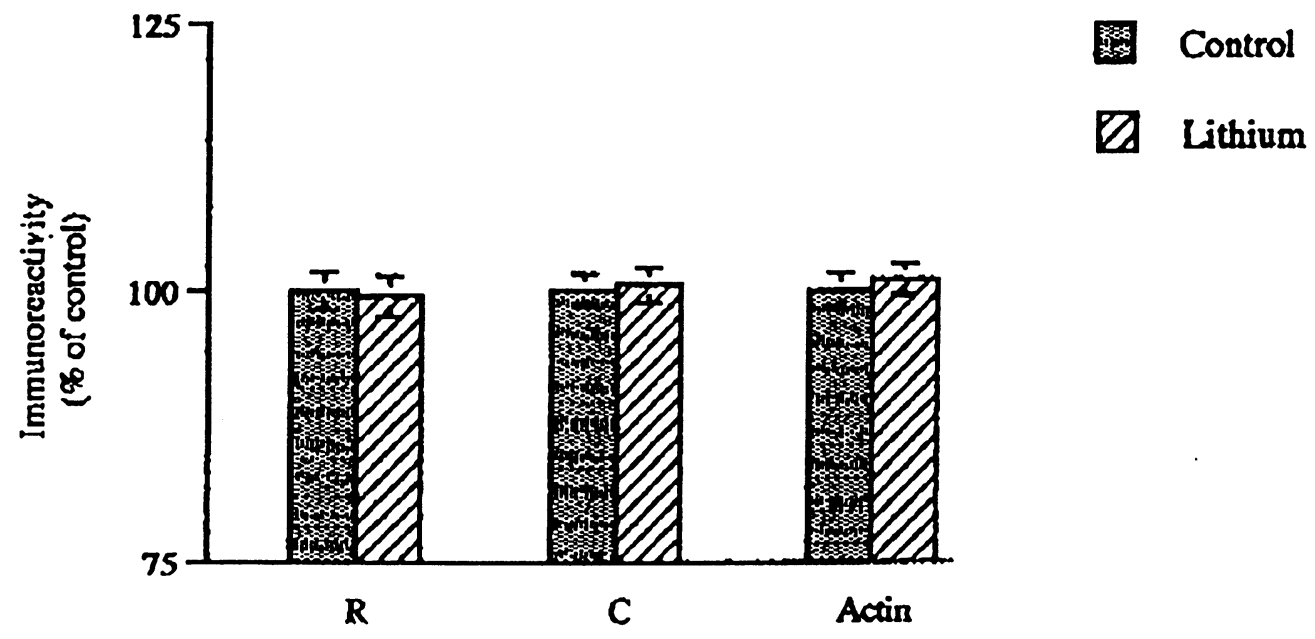

Figure 3. Influence of chronic lithium treatment on the immunolabeling of the regulatory (R) and catalytic (C) subunits of PKA and of actin in the soluble (upper panel) and particulate (lower panel) fractions of frontal cortex. Data are expressed as percentage of control \pm standard deviation. ${ }^{*} p=.005,{ }^{* *} p=.01$ (Student's $t$-test). 


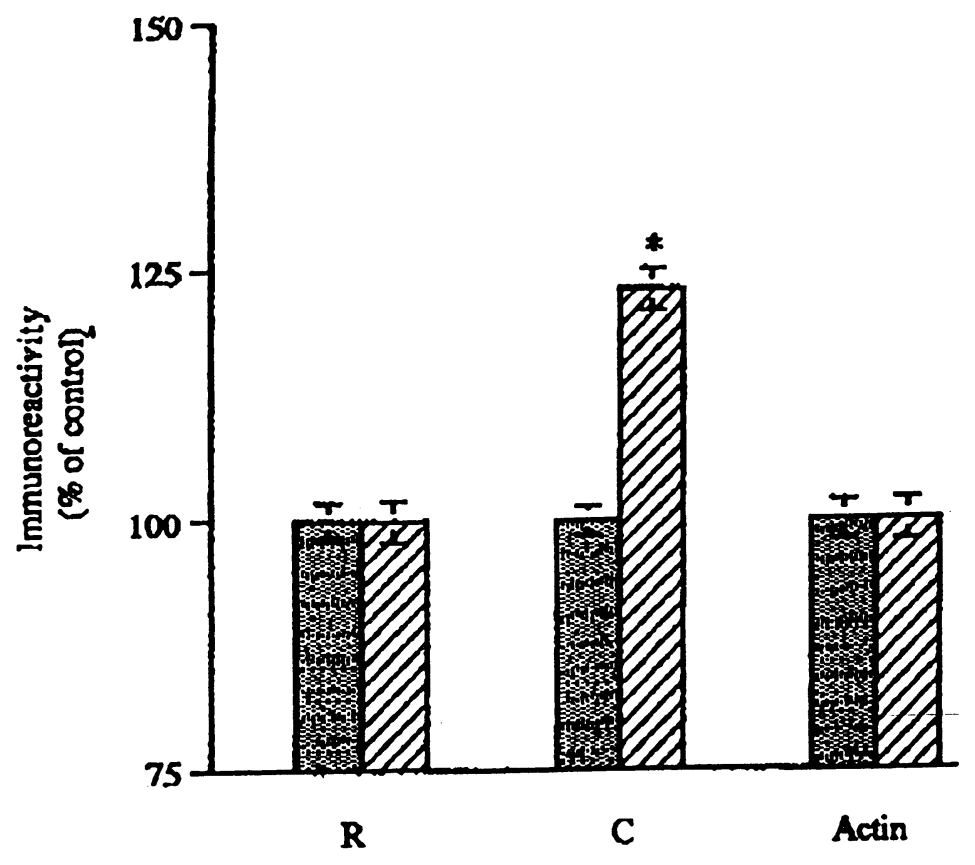

\section{Control \\ D Lithium}

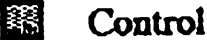 \\ $B$ Lithium}

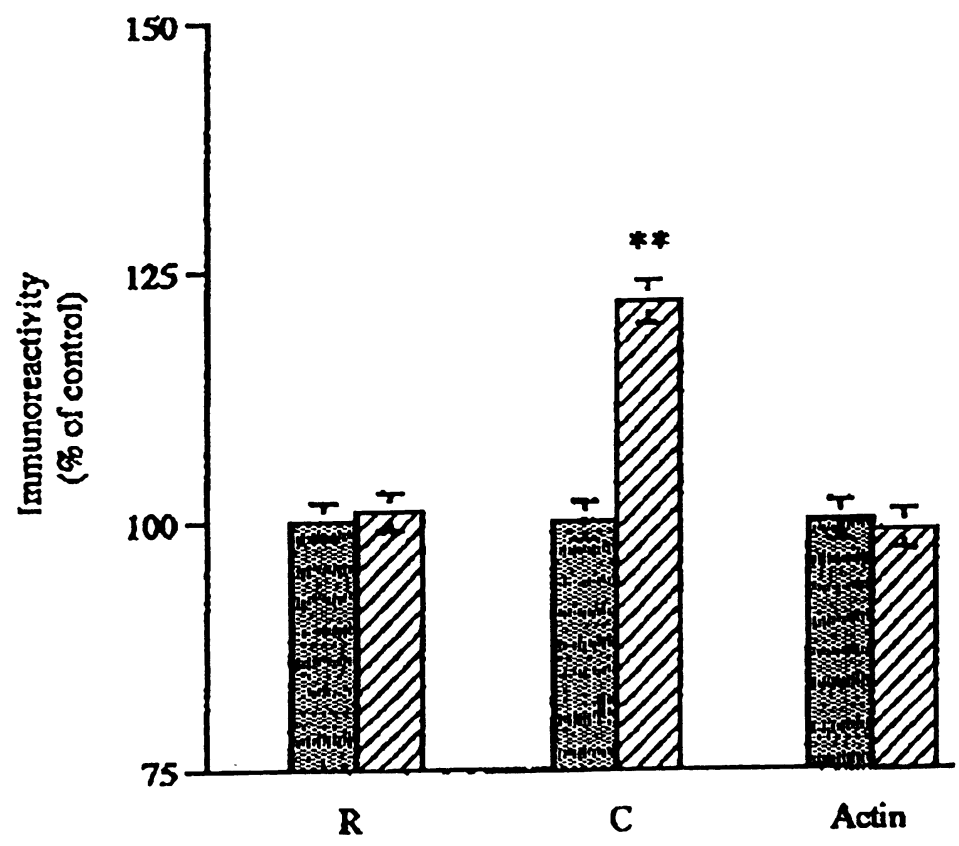

Figure 4. Effect of short-term lithium treatment on the immunolabeling of the regulatory (R) and catalytic (C) subunits of PKA and of actin in the soluble fraction of hippocampus (upper panel) and frontal cortex (lower panel). Results are expressed as percentage of control \pm standard deviation. ${ }^{*} p=.001,{ }^{* *} p=.03$ (Student's $t$-test). 
cologic treatment (Nestler et al. 1989). However, the latter possibility is unlikely, because the cAMP binding to the $52 \mathrm{kDa}$ protein as well as the immunoreactivity in particulate fraction were not significantly different between untreated and lithium-treated rats. Again, it is unlikely that the increase in PKA levels may be the result of a general alteration of proteins, because the immunolabeling for actin, in the soluble as well as in the particulate fractions, was unchanged in controls and treated rats. In conclusion, the results herein reported indicated that besides G-proteins, adenylate cyclase and phosphoproteins, the PKA could play also a crucial role in the biochemical action of lithium.

\section{REFERENCES}

Caselbot TL, Jope RS (1991): Effects of chronic lithium treatment on protein kinase $\mathrm{C}$ and cyclic AMP-dependent protein phosphorylation. Biol Psychiatry 29:233-243

Colin SF, Chang HC, Mollner S, Pfeuffer T, Reed RR, Duman RS, Nestler EJ (1991): Chronic lithium regulates the expression of adenylate cyclase and $\mathrm{G}_{\mathrm{i}}$ protein $\alpha$ subunit in rat cerebral cortex. Proc Natl Acad Sci USA 88:1063410637

Guitart X, Nestler EJ (1992): Chronic administration of lithium or other antidepressants increases levels of DARPP32 in rat frontal cortex. J Neurochem 59:1164-1167

Hyman SE, Nestler EJ (1996): Initiation and adaption: A paradigm for understanding psychotropic drug action. Am J Psychiat 153:151-162

Hudson CJ, Young LT, Li PP, Warsh JJ (1993): CNS signal transduction in the pathophysiology and pharmacotherapy of affective disorders and schizophrenia. Synapse 13:278-293

Jope RS, Williams MB (1994): Lithium and brain signal transduction system. Biochem Pharmacol 47:429-441

Laemmli UK (1970): Cleavage of structural proteins during the assembly of the head of the bacteriophage $\mathrm{T}_{4}$. Nature 227:680-685

Lesch KP, Aulakh CS, Tolliver TJ, Hill JL, Wolozin BL, Murphy DL (1991): Differential effects of long-term lithium and carbamazepine administration of $\mathrm{G}_{\mathrm{S} \alpha}$ and $\mathrm{G}_{\mathrm{i} \alpha}$ protein on rat brain. Eur J Pharmacol 207:355-359

Li PP, Tam YK, Young LT, Warsh JJ (1991): Lithium decreases $G_{s}, G_{i 1}$, and $G_{i 2 \alpha}$ subunit mRNA levels in rat cortex. Eur J Pharmacol 206:165-166

Manji HK, Potter WZ, Lenox RH (1995): Signal transduction pathways: Molecular targets for lithium's actions. Arch Gen Psychiat 52:531-543
Masana MI, Bitran JA, Hsiao JK, Potter WZ (1992): In vivo evidence that lithium inactivates $G_{i}$ modulation of adenylate cyclase activity in brain. J Neurochem 59:200-205

Mori S, Zanardi R, Popoli M, Smeraldi E, Racagni G, Perez J (1996): Inhibitory effect of lithium on cAMP dependent phosphorylation system. Life Sci 59:99-104

Mork A, Geisler A (1989): Effects of GTP on hormone-stimulated adenylate cyclase activity in cerebral cortex, striatum, and hippocampus from rats treated chronically with lithium. Biol Psychiat 26:279-288

Nestler EJ, Terwillinger RZ, Duman RS (1989): Chronic antidepressant administration alters the subcellular distribution of cyclic AMP-dependent protein kinase in rat frontal cortex. J Neurochem 53:1644-1647

Newman ME, Shapira B, Lerer B (1991): Effects of lithium and desipramine on second messenger responses in rat hippocampus: Relation to G protein effects. Neuropharmacology 30:1297-1301

Perez J, Tinelli D, Brunello N, Racagni G (1989): cAMPDependent phosphorylation of soluble and crude microtubule fractions of rat cerebral cortex after prolonged desmethylimipramine treatment. Eur J Pharmacology Mol Pharmacol Sec 172:305-316

Perez J, Tinelli D, Bianchi E, Brunello N, Racagni G (1991): cAMP binding proteins in the rat cerebral cortex after administration of selective 5HT and NE reuptake blockers with antidepressant activity. Neuropsych 4:57-64

Price LH, Heninger GR (1994): Lithium in the treatment of mood disorders. New Engl J Med 331:591-598

Racagni G, Brunello N, Tinelli D, Perez J (1992): New biochemical hypotheses on the mechanism of action of antidepressant drugs: cAMP-Dependent phosphorylation system. Pharmacopsychiatry 25:51-55

Rocha E, Rodnight R (1994): Chronic administration of lithium chloride increases immunodetectable glial acidic protein in the rat hippocampus. Neurochemistry 63: 1582-1584

Scott JD (1991): Cyclic nucleotide dependent protein kinases. Pharm Ther 50:123-145

Walaas S, Naim AC, Greengard P (1983a): Regional distribution of calcium and cyclic adenosine $3^{\prime}, 5^{\prime}$-mono-phosphateregulated protein phosphorylation system in mammalian brain. (I. Particulate system). J Neurosci 3:291

Walaas S, Naim AC, Greengard P (1983b): Regional distribution of calcium and cyclic adenosine $3^{\prime}, 5^{\prime}$-mono-phosphate-regulated protein phosphorylation system in mammalian brain. (II. Soluble system). J Neurosci 3:302

Walaas S, Greengard P (1991): Protein phosphorylation and neuronal function. Pharmacol Rev 43:299-349

Wood AJ, Goodwin GM (1987): A review of biochemical and neuropharmacological actions of lithium. Psychol Med $17: 579-600$ 